\title{
https://doi.org/10.46813/2021-136-107 \\ INVESTIGATION OF PLASMOCHEMICAL DISSOCIATION OF HYDROGEN SULFIDE IN INTENSIVE SWIRL FLOWS
}

\author{
Z.O. Znak \\ Lviv Polytechnic National University, Lviv, Ukraine \\ E-mail: zenovii.o.znak@lpnu.ua
}

\begin{abstract}
The process of plasmochemical decomposition $\mathrm{H}_{2} \mathrm{~S}$ in a rotating reactor is studied. The generation of ultrahighfrequency radiation in pulsed mode was synchronized with the rotation of the rotor. The influence of the rotor speed on the formation of the region of existence of a plasma discharge in the reactor and separation of $\mathrm{H}_{2} \mathrm{~S}$ decomposition products are established. The content of hydrogen and hydrogen sulfide in the gas phase was analyzed at different points of the reactor along its radius. The concentration of $\mathrm{H}_{2}$ and $\mathrm{H}_{2} \mathrm{~S}$ was determined by chromatography.
\end{abstract}

PACS: 50., 52.35., 52.50, $82.33 \mathrm{Xj}$

\section{INTRODUCTION}

The depletion of natural fuel resources and constant fluctuations in their production volumes make it necessary to intensively develop alternative energy, in particular, hydrogen energy [1]. Of considerable interest is the production of hydrogen from $\mathrm{H}_{2} \mathrm{~S}$ [2], in particular, by plamachemical method [3]. Hydrogen sulphide is formed in the processes of oil refining and natural gas purification [4]. A powerful promising source of hydrogen sulphide is the Black Sea, which contains at least 10 billion tons of this gas [5]. During the plasmachemical decomposition of $\mathrm{H}_{2} \mathrm{~S}$ sulphur is formed simultaneously with hydrogen as an additional product [6]

$$
\mathrm{H}_{2} \mathrm{~S} \Leftrightarrow \mathrm{nH}_{2}+\mathrm{S}_{\mathrm{n}} \text {. }
$$

It provides an increase in the completeness of processing of hydrogen sulphide raw materials and an increase in the technical and economic indicators of the process, especially if special types of sulphur are obtained, in particular, polymeric sulphur [7].

Since the $\mathrm{H}_{2} \mathrm{~S}$ decomposition process is equilibrium, the decomposition products (hydrogen and sulphur) must be separated to shift the equilibrium of the process to the right. For this purpose, a swirling gas flow is created in a plasma chemical reactor, which simultaneously makes it possible to stabilize the plasma discharge in the reactor [8]. But due to the small reactor radius, the separation efficiency is relatively negligible. In addition, the gas mixture at the outlet of a direct-flow plasma chemical reactor must be divided into components (hydrogen, sulphur and non-dissociated $\mathrm{H}_{2} \mathrm{~S}$ ). The aim of the work was to study the decomposition of hydrogen sulphide in a plasma-chemical reactor of the original design, in which an intense swirling gas flow is created using a rotor.

\section{EXPERIMENTAL}

The study was conducted on the installation (Fig. 1), which consisted of a reactor with a rotor, a rotor drive, an ultrahigh-frequency (microwave) radiation generator, and a device for creating a constant electric field (DCCEF).

Reactor (6) is a flat cylindrical chamber with a volume of $32.8 \mathrm{dm}^{3}$ and an internal diameter of $980 \mathrm{~mm}$. Inside it there is a rotor (7) connected through sealed seals to the drive, and ring electrodes (5) are mounted on insulators on the periphery. On the front end wall of the reactor (6) there is a rotor shaft seal and a fitting for supplying hydrogen sulphide, and on the rear - fittings (8) (at different radii) for sampling the gas phase for analysis, windows for visual observations, as well as a window through which microwave energy from the generator to reactor was supplied by rectangular microwave paths (12).

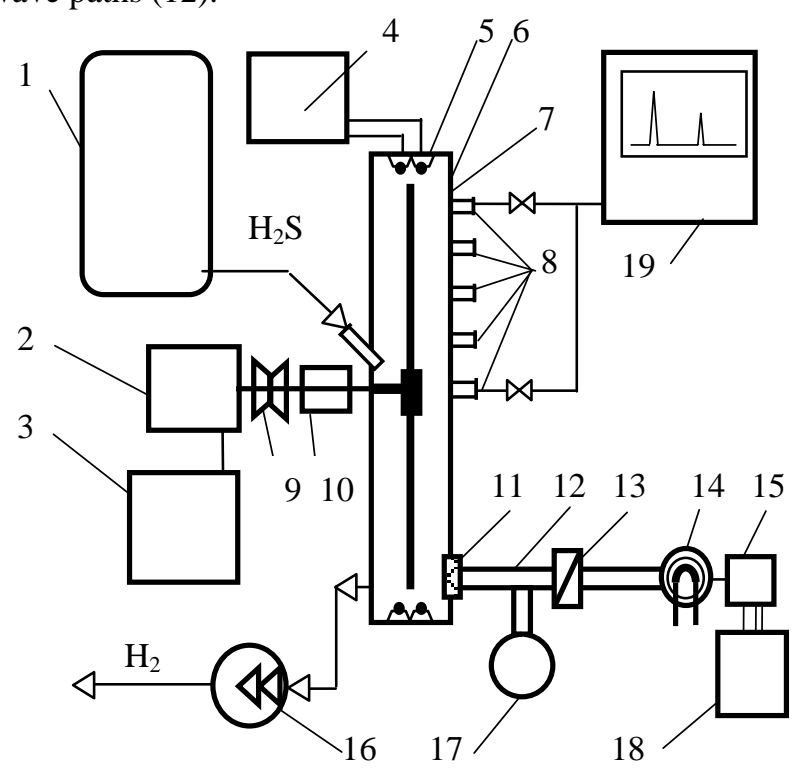

Fig. 1. Diagram of a rotary plasma chemical plant:

1 - gas tank; 2 - engine; 3 - engine control unit; 4 - high-voltage power supply unit; 5 - ring electrodes; 6 - reactor; 7 -rotor; 8 -fittings; 9 -coupling;

10 - multiplier; 11 -window; 12 - microwave path;

13 - switch; 14 - magnetron; 15 - microwave radiation modulator; 16 -vacuum pump; 17 -wattmeter;

18 - unit power supply; 19 - chromatograph

Microwave radiation with a frequency of $10 \mathrm{GHz}$ was generated using a pulsed magnetron IR-943 (3); the radiation power in the pulsed mode with a duration of 1 microsecond was $\sim 70 \mathrm{~kW}$, the integral power, which was regulated by the pulse repetition rate and the power of magnetron, was changed from 0.4 to $1.2 \mathrm{~kW}$. The pulse generation frequency was synchronized with the speed of rotation of the rotor, which was driven by a DC motor (2).

DCCEF in the form of a high-voltage DC source (4) is designed to create a stable electric field. The discharge circuit is made in the form of two annular elec- 
trodes (5) fixed symmetrically relative to the rotor (7). The electric field strength was varied within $4 . . .33 \mathrm{kV} / \mathrm{cm}$.

To condense the resulting sulfur, heat exchangers were mounted on the inner side of the cylindrical part of the reactor (see at Fig. 1 not shown).

Samples of the gas mixture for its analysis for hydrogen content were taken by evacuation. To determine the sulfur content in the gas mixture, which was analyzed for hydrogen content, a filter cartridge with basalt fiber was installed in front of the sampler to capture sulfur particles. The concentration of hydrogen and hydrogen sulfide in the gas phase was determined using an LChM-80 chromatograph (detector - catarometer, column $3 \mathrm{~m}$, sorbent - "Polysorb-1", temperature $-80^{\circ}$ $\mathrm{C}$; carrier gas - helium). To determine the amount of sulphur captured by the filter cartridge, it was washed with toluene, which is a good sulphur solvent. The sulphur content of toluene was determined spectrophotometrically on a Spekord M40 device (the comparison medium is toluene of the Qualification purity - "pure per analysis").

After vacuuming the reactor, the rotor drive was turned on and its speed was increased until the speed of the rotor ends reached $250 \ldots 350 \mathrm{~m} / \mathrm{s}$. after that, the DCCEF and the microwave radiation generator were turned on. The generation of the microwave pulse was synchronized with the rotation of the rotor in such a way that the pulse fell into the zone directly behind the rotor. In this zone, an aerodynamic rarefaction was created, which contributed to the occurrence of a plasma discharge. After that, hydrogen sulphide was fed to reactor (6) from a gas tank (1) with a given flow rate. The pressure in the reactor was maintained using a vacuum pump (16).

\section{RESULTS AND DISCUSSION}

It is established that the degree of decomposition of hydrogen sulphide significantly depends on the power and mode of microwave radiation generation, the voltage in the discharge circuit and the speed of rotation of the rotor. With an increase in the integrated power of the microwave generator from 0.4 to $1.2 \mathrm{~kW}$ at a rotor speed of about $6000 \mathrm{rpm}$., the discharge circuit voltage of $20 \pm 0.5 \mathrm{kV}$, the pressure in reactor of $0.07 \pm 0.005 \mathrm{MPA}$ and the volume flow rate of hydrogen sulphide $(8.3 \pm 0.4) \cdot 10^{-4} \mathrm{~m}^{3} / \mathrm{s}$, the degree of decomposition of $\mathrm{H}_{2} \mathrm{~S}$ increased almost rectilinearly from 15.7 to $35.1 \%$ (Table).

As can be seen from the results obtained, the total energy consumption for $\mathrm{H}_{2} \mathrm{~S}$ decomposition in a rotary reactor decreases with increasing power of the microwave generator, in contrast to direct-flow plasma torches. This effect can be explained by a more efficient use of microwave energy due to the expansion of the region of existence of the plasma discharge in the reactor. This area is formed along the trajectory of the rotor, which is observed even visually (Fig. 2). A similar effect was achieved with an increase in the voltage in the discharge circuit (at a constant power of microwave radiation). For example, at a voltage of $5 \ldots 8 \mathrm{kV}$ discharge zone is localized near the point of input of microwave energy into the reactor (see Fig. 2,a). As the voltage increases, the discharge zone stretches along the trajectory of the rotor. This phenomena is explained by the fact that in the discharge circuit between annular electors, the gas medium is partially ionized and acquires conductivity. Therefore, when microwave energy is introduced into this zone, it moves in an ionized medium as in a conductor. In this case, a combined microwave discharge occurs with a DC discharge. The discharge zone, which was recorded by the intensity of light radiation, expands and stretches. It is clear that under these conditions, the volume in which the plasma discharge exists increases, which leads to an increase in the degree of dissociation of hydrogen sulfide. If the voltage increases to $16 \ldots 18 \mathrm{kV}$ an almost continuous annular discharge region of is formed (see Fig. 2,b), which leads to a further increase in the degree of $\mathrm{H}_{2} \mathrm{~S}$ dissociation.

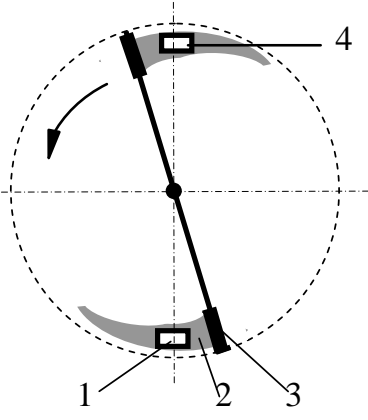

$a$

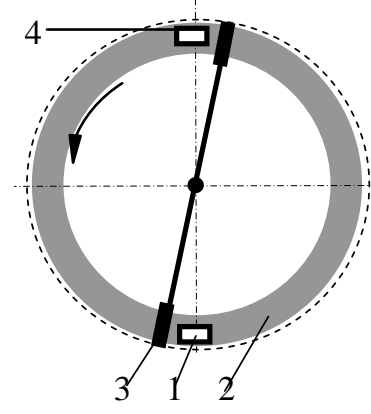

$b$
Fig. 2. Diagram of formation of the plasma discharge region in a rotary reactor at a radiation power of $0.8 \mathrm{~kW}$ from the voltage in the discharge circuit $(\mathrm{kV})$ : $a-5 \ldots 8 ; b->16 ; 1-$ window for input of microwave radiation; 2 - area of existence of a plasma discharge;

3 -rotor; 4 - window for visual observations

When the voltage in the discharge circuit increases from 5 to $21 \mathrm{kV}$, the degree of decomposition of hydrogen sulphide (at a microwave radiation power $0.8 \mathrm{~kW}$ and a pressure $0.78 \mathrm{MPA}$ ) increases from 12 to $38 \%$.

The speed of rotation of the rotor and, accordingly, the linear speed of movement of its ends affect not only the degree of dissociation of hydrogen sulfide, but also the separation of plasmolysis products and the formation of polymer modification of sulfur.

With an increase in the speed of rotation of the rotor, the area where there is aerodynamic shading and, accordingly, a decrease in pressure, the zone of formation of the plasma discharge expands both in the direction of rotation of the rotor and radially. At low rotor speeds $(\sim 1500 \mathrm{rpm})$ the discharge is formed in the form of a rather narrow segment, and when the rotor speed reaches $6000 \mathrm{rpm}$ - in the form of a ring with a stable glow intensity (Fig. 3).

At the same time, the duration of hydrogen sulfide stay in the discharge zone increases, and the degree of its dissociation, as expected, increases. So, at rotor speeds of 1500, 3000, 4500 and $6000 \mathrm{rpm}$ the corresponding average values of the degree of decomposition of $\mathrm{H}_{2} \mathrm{~S}$ (pressure $0.06 \mathrm{MPA}$, discharge circuit voltage $15 \mathrm{kV}$, microwave power $0.8 \mathrm{~kW}$ ) are $12.2,16.0,22.3$ and $35.1 \%$. 
Influence of microwave generator power on the degree of decomposition of hydrogen sulphide (a rotor speed of $6000 \mathrm{rpm}$, the pressure in is $0.07 \pm 0.005 \mathrm{MPa}$ )

\begin{tabular}{|c|c|c|c|c|c|}
\hline $\begin{array}{c}\text { Power } \\
\text { of vicrowave } \\
\text { generator, } \mathrm{kW}\end{array}$ & $\begin{array}{c}\text { Consumption } \\
\text { of } \mathrm{H}_{2} \mathrm{~S}, \\
\mathrm{~V} \cdot 10^{4}, \mathrm{~m}^{3} / \mathrm{s}\end{array}$ & $\begin{array}{c}\text { Discharge of } \\
\text { circuit voltage, } \\
\mathrm{kV}\end{array}$ & $\begin{array}{c}\text { Power } \\
\text { of discharge } \\
\text { circuit, } \mathrm{kW}\end{array}$ & $\begin{array}{c}\text { Degree of de- } \\
\text { composition } \\
\mathrm{H}_{2} \mathrm{~S}, \%\end{array}$ & $\begin{array}{c}\text { Total specific energy } \\
\text { consumption, } \\
\mathrm{kW} \cdot \mathrm{h} / \mathrm{m}^{3}\end{array}$ \\
\hline 0.40 & 8.3 & 19.8 & 0.68 & 15.7 & 2.29 \\
\hline 0.55 & 8.2 & 20.5 & 0.72 & 21.4 & 2.01 \\
\hline 0.66 & 8.7 & 19.5 & 0.65 & 21.5 & 1.94 \\
\hline 0.74 & 8.4 & 20.1 & 0.70 & 24.6 & 1.93 \\
\hline 0.87 & 7.9 & 20.5 & 0.73 & 31.2 & 1.80 \\
\hline 0.98 & 8.5 & 19.9 & 0.69 & 31.6 & 1.73 \\
\hline 1.20 & 8.3 & 20.1 & 0.68 & 35.1 & 1.78 \\
\hline
\end{tabular}

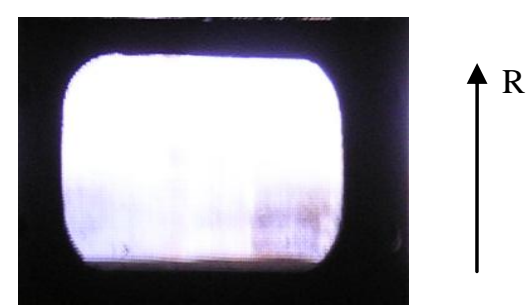

Fig. 3. Fragment of the plasma discharge zone in the reactor (foto)

Separation of hydrogen sulfide plasmolysis products occurs due to the action of centrifugal force (Fig. 4).

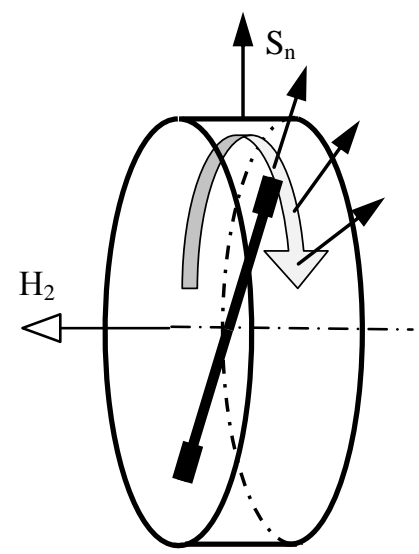

Fig. 4. Scheme of separation of hydrogen sulfide plasmolysis products in a rotary reactor

It is established that with an increase in the speed of rotation of the rotor, the efficiency of separation of components of the gas mixture formed as a result of dissociation of hydrogen sulphide increases, and the concentration of hydrogen near the reactor axis increases (Fig. 5). For example, at a rotor speed of $6000 \mathrm{rpm}$. and the degree of dissociation of $\mathrm{H}_{2} \mathrm{~S} 37 \%$ the concentration of hydrogen in the center of the reactor reaches $91 \%$. In this case, the degree of concentration of hydrogen $\left(\alpha\left(\mathrm{H}_{2}\right)\right)$ is 2.46 the degree of concentration of hydrogen in the swirling flow was calculated by the equation

$$
\alpha\left(H_{2}\right)=\frac{C\left(H_{2}\right)_{\mathrm{R}=0}}{C\left(H_{2}\right) *},
$$

where $C\left(\mathrm{H}_{2}\right)_{R=0}$ - concentration of $\mathrm{H}_{2}$ in the center of the reactor, \%; $\mathrm{C}\left(\mathrm{H}_{2}\right)^{*}$ - equilibrium concentration of $\mathrm{H}_{2}$ corresponding to the degree of dissociation of $\mathrm{H}_{2} \mathrm{~S}$, $\%$.

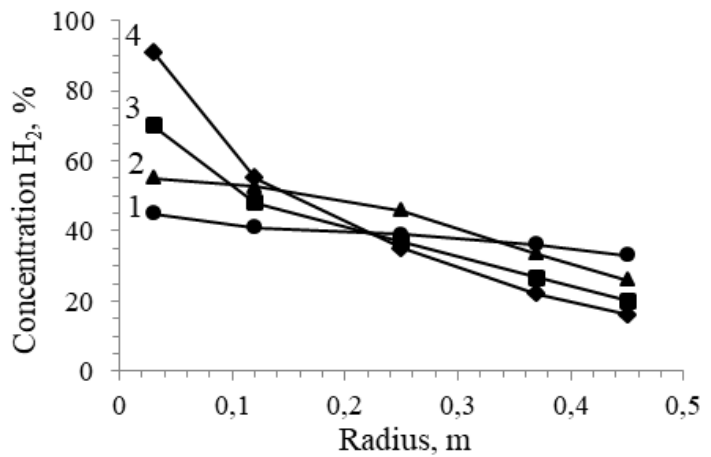

Fig. 5. Hydrogen concentration profiles along the reactor radius by the degree of decomposition of $\mathrm{H}_{2} \mathrm{~S} 37 \%$; rotor speed, rpm: 1 - 1500; 2-3000; 3-4500; 4-6000

At a lower rotor speed (4500, 3000 and $1500 \mathrm{rpm})$ the maximum concentration of $\mathrm{H}_{2}$ was 70,56 and $46 \%$, and the degree of concentration was $1.89,1.49$ and 1.22, respectively.

Under the action of centrifugal force, heavier than $\mathrm{H}_{2}, \mathrm{H}_{2} \mathrm{~S}$ molecules move to the periphery, that is, to the region of plasma discharge, which increases the probability of its dissociation.

In the gas phase samples taken from fittings located at a distance of 50, 250 and $500 \mathrm{~mm}$ from the axis of the cylindrical reactor vessel, condensed sulfur was not detected in any of the samples. In samples taken from fittings at a distance of 750 and $900 \mathrm{~mm}$ from the axis, the sulfur content slightly increased with increasing distance and with decreasing rotor speed. However, a clear pattern of sulfur content from the distance from the reactor axis was not found. This can be explained by two factors. First, under the action of centrifugal forces on sulfur clusters, which are formed as a result of the molecular characterization of sulfur atoms as primary products of hydrogen sulfide dissociation $\left(\mathrm{nS} \rightarrow \mathrm{S}_{\mathrm{n}}(2 \leq\right.$ $\mathrm{n} \leq 20$ )) [9], centrifugal drift intensifies. As the degree of $\mathrm{H}_{2} \mathrm{~S}$ decomposition increases, the local concentration of atomic sulfur and the probability of forming clusters with a higher molecular weight increase. Secondly, due to the existence of a radial pressure gradient in the reactor (an increase towards the periphery), the probability of formation of sulfur clusters obviously increases. Accordingly, the effect of centrifugal force increases. Third, the presence of sulfur in gas phase samples taken at a distance of $750 \mathrm{~mm}$ from the axis is probably due to the occurrence of circulation flows in the peripheral regions of the reactor. Due to this, some of the lowmolecular sulfur clusters in the form of gaseous or con- 
densed products are transferred to the region closer to the reactor axis.

The data obtained clearly indicate that gas-phase substances can be efficiently separated in a rotary reactor. According to calculations for the degree of dissociation of hydrogen sulfide $37 \%$, the hydrogen concentration equal to $100 \%$ will be reached at a rotor speed of about $6500 \mathrm{rpm}$. It is obvious that if a higher degree of hydrogen sulfide dissociation is achieved, the separation efficiency of the gas mixture will increase. Due to this, there will be no need to achieve the greatest possible degree of dissociation of hydrogen sulfide, which will lead to a significant increase in energy consumption.

The obtained results of plasmochemical dissociation of hydrogen sulfide in intensive swirling flows became the basis for the development of a new cascade-modular concept for the implementation of the technological process of hydrogen sulfide processing.

\section{CONCLUSIONS}

The possibility of simultaneous implementation of the process of $\mathrm{H}_{2} \mathrm{~S}$ Plasmolysis and separation of medium components in one apparatus is confirmed. At a rotor speed of $6000 \mathrm{rpm}$ and the degree of dissociation of $\mathrm{H}_{2} \mathrm{~S}$ is only $37 \%$ the concentration of hydrogen in the center of the reactor is $91 \%$.

\section{REFERENCES}

1. Hydrogen: a renewable energy perspective: Report prepared for the 2nd Hydrogen Energy Ministerial Meeting in Tokyo, Japan, 2019, 52.
2. A.N. Startsev. Hydrogen sulfide as a source of hydrogen production // Russian Chemical Bulletin. 2017, v. 66, p. 1378-1397.

3. E.L. Reddy, V.M. Biju, Ch. Subrahmanyam. Production of hydrogen and sulfur from hydrogen sulfide assisted by nonthermal plasma // Applied Energy. 2012, v. 95, p. 87-92.

4. A.G. De Crisci, A. Moniri, Y. Xu. Hydrogen from hydrogen sulfide: towards a more sustainable hydrogen economy // International Journal of Hydrogen Energy. 2019, v. 44, v. 3, p. 1299-1327.

5. A. Demirbas. Hydrogen Sulfide from the Black Sea for Hydrogen Production // Energy Sources, Part A: Recovery, Utilization, and Environmental Effects. 2009, v. 31, v. 20, p. 1866-1872.

6. J. Zaman, A. Chakma. Production of hydrogen and sulfur from hydrogen sulfide // Fuel Processing Technology. 1995, v. 41, v. 2, p. 159-198.

7. Z.O. Znak, R.R. Olenych. Otrymannia stabilizovanoi polimernoi sirky plazmokhimichnym sposobom // Perspektyvni polimerni materialy ta tekhnolohii: monohrafiia / Za zah. red. V.P. Plavan. Kyiv: "KNUDT", 2015, p. 70-84 (in Ukrainian).

8. K.R. Gutsol, A. Rabinovich, A. Fridman. Dissociation of $\mathrm{H}_{2} \mathrm{~S}$ in non-equilibrium gliding arc tornado discharge // Int. J. Hydrogen Energy. 2009, v. 34, p. 7618-7625.

9. S.O. Macheret, V.D. Rusanov, A.A. Fridman, Neravnovesnaya klasterizatsiya $\mathrm{v}$ pole tsentrobezhnyih sil i dissotsiatsii molekul v plazme // Zhurnal tehnicheskoy fiziki. 1987, v. 57, v. 4, p. 712720.

Article received 06.10.2021

\section{ИССЛЕДОВАНИЕ ПЛАЗМОХИМИЧЕСКОЙ ДИССОЦИАЦИИ СЕРОВОДОРОДА В ИНТЕНСИВНЫХ ЗАКРУЧЕННЫХ ПОТОКАХ}

\section{0. Знак}

Исследован процесс плазмохимического разложения $\mathrm{H}_{2} \mathrm{~S}$ в реакторе роторного типа. Генерирование сверхвысокочастотного излучения в импульсном режиме синхронизировали с вращением ротора. Установлено влияние частоты вращения ротора на формирование области существования плазменного разряда в реакторе и сепарацию продуктов разложения $\mathrm{H}_{2} \mathrm{~S}$. Газовую фазу на содержание водорода и сероводорода определяли в различных точках реактора по его радиусу. Концентрации $\mathrm{H}_{2}$ и $\mathrm{H}_{2} \mathrm{~S}$ определяли хроматографически.

\section{ДОСЛІДЖЕННЯ ПЛАЗМОХІМІЧНОЇ ДИСОЦІАЦІЇ СІРКОВОДНЮ В ІНТЕНСИВНИХ ЗАКРУЧЕНИХ ПОТОКАХ}

\section{O. Знак}

Досліджено процес плазмохімічного розкладу сірководню в реакторі роторного типу. Генерування надвисокочастотного випромінювання в імпульсному режимі синхронізували з обертанням ротора. Встановлено вплив частоти обертання ротора на формування області існування плазмового розряду в реакторі та сепарацію продуктів розкладу $\mathrm{H}_{2} \mathrm{~S}$. Газову фазу на вміст водню та сірководню визначали в різних точках реактора по радіусу реактора. Концентрації $\mathrm{H}_{2}$ i $\mathrm{H}_{2} \mathrm{~S}$ визначали хроматографічно. 